\title{
Does the peroxidase-like activity of sodium dodecyl sulphate-modified cytochrome $c$ increase after peroxynitrite or radiation treatment? ${ }^{\star}$
}

\author{
Lidia Gębicka ${ }^{\bowtie}$ and Joanna Didik \\ Institute of Applied Radiation Chemistry, Technical University of Łódź, Łódź, Poland; \\ 凶e-mail:lgebicka@mitr.p.lodz.pl
}

Received: 10 December, 2004; revised: 12 January, 2005; accepted: 03 February, 2005

available on-line: 15 May, 2005

\begin{abstract}
The peroxidase-like activity of cytochrome $c$ is considerably increased by unfolding of the protein. The enhancement of the activity is due to the higher reaction rate of unfolded cytochrome $c$ with hydrogen peroxide, which is the rate-determining step in the peroxidase cycle of cytochrome $c$ (Gębicka, L., 2001, Res Chem Intermed 27, 717-23). In this study we checked whether combined action of two unfolding factors, SDS and peroxynitrite or radiation (hydroxyl radicals), increases the peroxidase-like activity of cytochrome $c$ more than any single treatment alone. Peroxynitrite reacts with SDS-modified cytochrome $c$ in the same way as with native cytochrome $c$, via intermediate radical products, $\bullet \mathrm{OH} / \mathrm{NO}_{2}$, arising from peroxynitrite homolysis. We found that SDS-modified cytochrome $c$ is much more sensitive to oxidative damage than the native protein. Partial unfolding of cytochrome $c$ by SDS causes the peroxide substrate to have a better access to the heme center. On the other hand, the amino acids located in the vicinity of the active site and/or heme group become accessible for oxidizing radicals. The overall effect observed is that the peroxidase-like activity of SDS-modified cytochrome $c$ decreases with an increase of the concentration of the oxidizing species (peroxynitrite or radiolytically generated hydroxyl radicals). The damage of SDS-modified cytochrome $c$ caused by irradiation is much more significant than that observed after peroxynitrite treatment.
\end{abstract}

Keywords: cytochrome $c$, peroxidatic activity, peroxynitrite; radiation, SDS

Cytochrome $c$ is a heme protein that participates in the electron transfer in the respiratory chain. Recently it has been discovered that cytochrome $c$, under certain stimulation is released from mitochondria into the cytosol, where it takes part in the propagation of the apoptotic cascade ( $\mathrm{Li}$ et al., 1997; Kluck et al., 1997; Skulachev, 1998). In this process a conformational transition of cytochrome $c$ molecule to the non-native B2 states has been suggested. It has been proposed that similar changes in the cytochrome $c$ molecule can be induced by the anionic surfactant sodium dodecyl sulphate (SDS) (Oellerich et al., 2003).

A common characteristic of the non-native B2 states is the dissociation of the axial Met80 ligand from the heme iron and its replacement by His33 (His26), or leaving the sixth coordination position unoccupied (Oellerich et al., 2002). Another indicator of the non-native states of cytochrome $c$ is its perox- idase-like activity. It has been shown that when the structure of cytochrome $c$ is perturbed, e.g. by unfolding, its peroxidase-like activity increases considerably. For example, increased peroxidase activity has been reported for cytochrome $c$ in the presence of phospholipid bilayer membrane (Hamachi et al., 1994), or ionic surfactants (Gębicka, 2001; Diederix et al., 2004), when unfolded by guanidinium hydrochloride (Diederix et al., 2002), oxidized by reactive halogen species (Chen et al., 2002), or by hydroxyl and $\mathrm{CO}_{3}^{-\bullet}$ radicals generated radiolytically (Gębicka \& Didik, 2003), as well as when modified by peroxynitrite (Cassina et al., 2000; Gębicka \& Didik, 2003). The enhancement of the peroxidase-like activity is due to the higher reaction rate of cytochrome $c$ with $\mathrm{H}_{2} \mathrm{O}_{2}$, which is the rate-determining step in the peroxidase cycle of cytochrome $c$. Despite a lack of spectroscopic evidence, it is generally accepted that $\mathrm{H}_{2} \mathrm{O}_{2}$ oxidizes cytochrome $c$ to a ferryl-radical com-

-Preliminary report was presented at the 13th Meeting of the Maria Skłodowska-Curie Polish Society of Radiation Research, 13-16 September, 2004, Łódź, Poland.

Abbreviations: ABTS, 2,2'-azino-bis[ethyl-benzothiazoline-(6)-sulphonic acid]; CMC, critical micelle concentration; SDS, sodium dodecyl sulphate. 
pound I-type intermediate. The radical site, initially located on the porphyrin ring, is rapidly transferred to tyrosine (Barr et al., 1996; Chen el al., 2002; Lawrence et al., 2003). It is possible that in the absence of reducing substrates compound I of cytochrome $c$ oxidizes amino acids located in the vicinity of heme or heme itself (Barr et al., 1996). As a result, the Soret absorbance spectrum bleaches (Florence, 1985; Radi et al., 1991; Villegas et al., 2000; Gębicka, 2001; Castro et al., 2004).

It is worth noting that both SDS monomers and micelles interact with cytochrome $c$ (Otzen \& Oliveberg, 2002; Oellerich et al., 2003). The peroxidatic activity of cytochrome $c$ increases with the increase of SDS concentration to reach plateau after exceeding critical micelle concentration (CMC) (Gębicka, 2001; Diederix et al., 2004).

Peroxynitrite $\left(\mathrm{ONOO}^{-} / \mathrm{ONOOH}\right)$ is a strong oxidizing and nitrating agent generated from a nearly diffusion controlled reaction of nitric oxide with superoxide. Whereas peroxynitrite anion is stable, peroxynitrous acid $(\mathrm{pK}=6.8)$ rapidly isomerizes to nitrate, partially (about $30 \%$ ) via ${ }^{\circ} \mathrm{OH}$ and ${ }^{\circ} \mathrm{NO}_{2}$ radicals (for a recent review see Augusto et al., 2002). It is generally accepted that many reactions of peroxynitrite with inorganic and organic substrates are primarily induced by these two radicals (Kirsch et al., 2003). There are, however, substrates which are oxidized directly by peroxynitrite (Goldstein \& Czapski, 1995). Many heme proteins react with peroxynitrite in a similar way as with $\mathrm{H}_{2} \mathrm{O}_{2}$, i.e. peroxynitrite oxidizes heme iron to form a ferryl heme derivative, which in turn reacts with a second peroxynitrite molecule or other substrate to restore native enzyme (Floris et al., 1993; Gębicka \& Gębicki, 2000; Herold \& Shivashankar, 2003). As a result, faster peroxynitrite decay is observed in the presence of such reagents. On the other hand, ferric heme iron in native cytochrome $c$ does not react with peroxynitrite. Intermediate products of peroxynitrite decomposition, ${ }^{\circ} \mathrm{OH} /{ }^{\circ} \mathrm{NO}_{2}$ radicals, are the species responsible for cytochrome $c$ modification (Gębicka \& Didik, 2003).

As the conformational changes which take place in SDS-treated cytochrome $c$ as well as modification of cytochrome $c$ by radicals from peroxynitrite decomposition facilitate the reaction of heme iron with $\mathrm{H}_{2} \mathrm{O}_{2}$ (enhanced peroxidase-like activity), we attempted in this study to check whether two unfolding factors, SDS and peroxynitrite or radiation (hydroxyl radicals), act synergistically in increasing the peroxidatic activity of cytochrome $c$.

\section{MATERIALS AND METHODS}

Peroxynitrite was prepared by the method described by Pryor et al. (1995). The final concentration of peroxynitrite was about $30 \mathrm{mM}$ as measured spectrophotometrically at $302 \mathrm{~nm}\left(\varepsilon=1670 \mathrm{M}^{-1} \mathrm{~cm}^{-1}\right.$ (Hudges \& Nicklin, 1968)). Stock solutions were stored at $-25^{\circ} \mathrm{C}$ and used within 3-4 weeks after synthesis.

Cytochrome $c$ from horse heart was obtained from Sigma. An absorption coefficient of $1.06 \times 10^{5}$ $\mathrm{M}^{-1} \mathrm{~cm}^{-1}$ at $410 \mathrm{~nm}$ (Goto et al., 1993) was used for spectrophotometric determination of cytochrome $c$ concentration. In all experiments, micellar solutions of SDS (from Sigma) were used. CMC of SDS in water is about $8 \mathrm{mM}$, but it decreases with increasing ionic strength and is about $4.5 \mathrm{mM}$ and $1 \mathrm{mM}$ in the presence of $10 \mathrm{mM}$ and $100 \mathrm{mM}$ Na-phosphate buffer, respectively (Reynolds \& Tanford, 1970).

The reaction of peroxynitrite with SDS-modified cytochrome $c$ was studied using an SX-17 Applied Photophysics stopped-flow spectrophotometer with a $1-\mathrm{cm}$ cell and with a mixing time $<1 \mathrm{~ms}$. Stock solutions of peroxynitrite were diluted to the appropriate concentration with $0.01 \mathrm{M} \mathrm{NaOH}$, cytochrome $c$ was dissolved in $0.02 \mathrm{M}$ SDS in $0.2 \mathrm{M}$ phosphate buffer, $\mathrm{pH}$ 7.0. Equal volumes of peroxynitrite and cytochrome $c$ were mixed in the cell and absorption changes were monitored at 302 and $404 \mathrm{~nm}$.

Autodecomposition of peroxynitrite was monitored at $302 \mathrm{~nm}$ after mixing peroxynitrite solution with $0.2 \mathrm{M}$ phosphate buffer, $\mathrm{pH} 7.0$ or with $0.02 \mathrm{M}$ SDS in $0.2 \mathrm{M}$ phosphate buffer, $\mathrm{pH}$ 7.0. Replicate mixing was performed outside of the stopped-flow apparatus to measure the $\mathrm{pH}$ of the reaction mixture. The process of mixing increased the $\mathrm{pH}$ by 0.1 unit.

Hydroxyl radicals were produced by $\gamma$-irradiation of $\mathrm{N}_{2} \mathrm{O}$-saturated aqueous solution of cytochrome $c$ with a dose rate of $0.025 \mathrm{~J} \mathrm{~kg}^{-1}$ per second. Radiolysis of water saturated with $\mathrm{N}_{2} \mathrm{O}$ leads to the conversion of all $\mathrm{e}^{-}$aq to ${ }^{\circ} \mathrm{OH}\left(0.54 \mu \mathrm{mol} \mathrm{J}{ }^{-1}\right.$ of hydroxyl radicals are generated (Buxton et al., 1988)). Under our experimental conditions the rate of ${ }^{\bullet} \mathrm{OH}$ formation was $13.5 \mathrm{nM}$ per second.

Absorption spectra and kinetic measurements in long-time regime were taken on a Hewlett-Packard 8452A diode-array spectrophotometer.

The peroxidase activity of cytochrome $c$ was assayed by the 2,2'-azino-bis[ethyl-benzothiazoline(6)-sulphonic acid] (ABTS) method (Childs \& Bardsley, 1975) at $\mathrm{pH} 7.0$ or 7.1 (small pH changes around pH 7 did not influence the rate of ABTS oxidation).

All kinetic measurements were carried out at $24 \pm 0.5^{\circ} \mathrm{C}$. Water from MilliQ Plus was used throughout.

\section{RESULTS AND DISCUSSION}

We found that peroxynitrite autodecomposes in $10 \mathrm{mM}$ aqueous solution of SDS, $\mathrm{pH} 7.1$ with the same rate as in the absence of SDS $\left(0.04 \pm 0.05 \mathrm{~s}^{-1}\right)$ 
(not shown). This means that SDS is not a scavenger for peroxynitrite. The rate of peroxynitrite decay did not change when cytochrome $c$ at micromolar concentrations was present in buffered SDS solution. Thus, SDS-modified cytochrome $c$, like its native form, does not catalyze decomposition of peroxynitrite (Gębicka \& Didik, 2003). Addition of an up to 50 -fold excess of peroxynitrite did not cause changes of the absorption spectrum of SDS-modified cytochrome $c$ in the Soret region. It should be noted that in the presence of SDS, the maximum of the Soret absorbance is blue shifted (from 410 to $407-400$ nm, depending on SDS concentration) (Gębicka \& Gębicki, 1998; Oellerich et al., 2003). We found that the rate of absorbance decay of SDS-modified cytochrome $c$, observed at $404 \mathrm{~nm}$, induced by a large excess of peroxynitrite, is the same as the rate of spontaneous peroxynitrite decay. This means that the absorbance changes of the Soret band of SDSmodified cytochrome $c$ are induced by intermediate radical products of $\mathrm{ONOOH}$ decomposition. However, the yield of bleaching (determined after correction for peroxynitrite absorbance at this wavelength) was approximately 2-fold higher than that observed for cytochrome $c$ in the absence of SDS after treatment by the same amount of peroxynitrite (Gębicka \& Didik, 2003).

Incubation of SDS-modified cytochrome c with peroxynitrite (the highest [peroxynitrite]/ [cytochrome] ratio was 1000) lowered the peroxidatic activity of this protein (Table 1), although it remained higher than that determined for native cytochrome c. During decomposition of peroxynitrite $\bullet \mathrm{OH}$ and ${ }^{\bullet} \mathrm{NO}_{2}$ are formed as intermediates. Hydroxyl radical reacts with all biological molecules at or near to diffusion-controlled rates. It causes damage closely to the site of its generation. Nitrogen dioxide is much more specific. It oxidizes cysteine, tryptophan and tyrosine as well as nitrates tyrosine and tryptophan. Nitration is significantly enhanced in the presence of ${ }^{\circ} \mathrm{OH}$ radicals. This is due to the fact that hydroxyl radical very quickly oxidizes tyrosine or tryptophan to phenoxyl or indolyl radical which then recombines with ${ }^{-} \mathrm{NO}_{2}$ (Augusto et al., 2002). The rate constants of the reaction of ${ }^{\bullet} \mathrm{OH}$ with cytochrome $c$, with SDS in the monomeric form, and with SDS micelles have been found to be $1.4 \times 10^{10}$ $\mathrm{M}^{-1} \mathrm{~s}^{-1}$ (Buxton et al., 1988), $7.9 \times 10^{9}$, and $5.0 \times 10^{8}$ $\mathrm{M}^{-1} \mathrm{~s}^{-1}$ (Bansal et al., 1971), respectively. Due to the large excess of SDS in the investigated system, the hydroxyl radicals generated during peroxynitrite decomposition react mainly with SDS molecules forming SDS $^{\bullet}$ radicals. The rate constants of SDS with inorganic radicals other than ${ }^{\circ} \mathrm{OH}$ are not high (Neta et al., 1988) and it seems that SDS is not a target for ${ }^{\bullet} \mathrm{NO}_{2}$. Evers et al. (1978) have suggested that $\mathrm{SDS}^{\bullet}$ radicals, produced radiolytically, cause degradation of the porphyrin ring of protoferriheme IX.
It is known that SDS binds to proteins. Under our experimental conditions probably all cytochrome $c$ molecules are complexed with SDS (Oellerich et al., 2003). This leads to partial unfolding of the protein and, as a consequence, hydrogen peroxide has a better access to the heme iron. On the other hand, it seems very likely that amino acids, which in native cytochrome $c$ are well buried, become accessible for reactive species in the SDS-modified protein molecule. Thus $\mathrm{SDS}^{\bullet}$ radicals formed during the reaction of SDS-modified cytochrome $c$ with peroxynitrite probably damage the amino acids located near the heme center, i.e. those involved in the reaction with $\mathrm{H}_{2} \mathrm{O}_{2}$. Damage of the heme group in cytochrome $c$ by $\mathrm{SDS}^{\bullet}$ radicals is also possible. As a result, lower peroxidase-like activity is observed.

We also measured absorption spectra and peroxidatic activity of SDS-modified cytochrome $c$ after exposure to hydroxyl radicals generated radiolytically. $\mathrm{N}_{2} \mathrm{O}$-saturated aqueous solutions of cytochrome $c$ $(4 \mu \mathrm{M})$ containing $10 \mathrm{mM}$ SDS were exposed to $\gamma$-irradiation. We observed that the rate of the decrease of the Soret band of cytochrome $c$ irradiated in the presence of SDS was significantly higher than that of cytochrome $c$ irradiated in the absence of SDS (Fig. 1). We have earlier shown that cytochrome $c$ modified by SDS is more sensitive to the destructive action of $\mathrm{H}_{2} \mathrm{O}_{2}$ (Gębicka, 2001). Under our experimental conditions, $6.3 \mu \mathrm{M} \mathrm{H}_{2} \mathrm{O}_{2}$ was produced in the system after absorbing a dose of $90 \mathrm{~Gy}$. We checked that incubation of SDS-treated cytochrome $c(4 \mu \mathrm{M})$ with $3 \times 10^{-5} \mathrm{M} \mathrm{H}_{2} \mathrm{O}_{2}$ for $1 \mathrm{~h}$ caused a decrease of absorbance at the Soret band by $20 \%$. The absorbance of native cytochrome $c$ treated with the same amount of $\mathrm{H}_{2} \mathrm{O}_{2}$ for $1 \mathrm{~h}$ did not change. Thus, generation of $\mathrm{H}_{2} \mathrm{O}_{2}$ during irradiation can be excluded as the main reason of heme destruction in SDS-modified cytochrome $c$. Taking into account the concentrations of cytochrome $c$ and SDS in the irradiated aqueous solution and their rate constants with $\bullet \mathrm{OH}$, under such experimental conditions, as well as in the experiments with peroxynitrite, one concludes that hydroxyl radicals react preferentially with SDS, forming $\mathrm{SDS}^{\bullet}$ radicals, which in turns react with cytochrome $c$. Peroxidase-like activity of SDS-modified cytochrome $c$ after radiation treatment decreases significantly with the dose (Fig. 2). On the other hand, cytochrome $c$ irradiated without SDS exhibits an increased peroxidatic activity, despite diminished absorbance of the Soret band (Gębicka \& Didik, 2003).

The damage of SDS-modified cytochrome $c$ caused by irradiation is much more significant than that observed after peroxynitrite treatment. For example, the peroxidase-like activity of SDS-modified cytochrome $c$ after irradiation with a dose of $90 \mathrm{~Gy}$ (about $50 \mu \mathrm{M} \cdot \mathrm{OH}$ is generated) is 20 times lower than that measured before irradiation (Fig. 2). On 


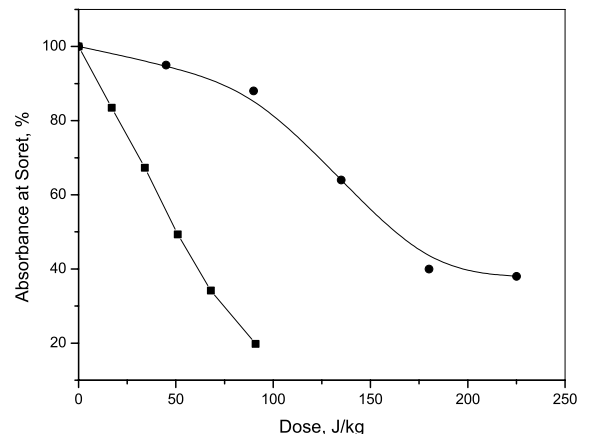

Figure 1. Relative absorbance changes (in \%) in the Soret band of cytochrome $c$ irradiated at micromolar concentration in $\mathrm{N}_{2} \mathrm{O}$-saturated aqueous solution in the absence $(\bullet)$ or in the presence of $10 \mathrm{mM}$ SDS (घ), pH $=7.0$ (5 mM phosphate buffer).

the other hand, the peroxidase-like activity of SDSmodified cytochrome $c$ decreases about 3.5 times after incubation with $0.8 \mathrm{mM}$ peroxynitrite (about $260 \mu \mathrm{M} \bullet \mathrm{OH}$ should be formed) (Table 1). During decomposition of peroxynitrite, the radical pair ${ }^{\bullet} \mathrm{OH} /{ }^{\bullet} \mathrm{NO}_{2}$ is formed. Part of $\mathrm{SDS}^{\bullet}$ radicals generated in the reaction with ${ }^{\circ} \mathrm{OH}$ may react with ${ }^{\circ} \mathrm{NO}_{2}$ and therefore the concentration of $\mathrm{SDS}^{\bullet}$ which attack the cytochrome $c$ molecule is much lower than that estimated from peroxynitrite concentration (assuming that all $\bullet \mathrm{OH}$ radicals react with SDS).

Summing up, SDS-modified cytochrome $c$ is much more sensitive to oxidative damage than the native protein. Partial unfolding of cytochrome $c$ molecule by SDS causes the peroxide substrate to have a better access to the heme center. On the other hand, amino acids located near the active site and/ or the heme group itself become accessible for oxidizing radicals. It has been reported that the radical formed on tyrosine residue as a result of the reaction of cytochrome $c$ with $\mathrm{H}_{2} \mathrm{O}_{2}$ plays an important role in heme destruction (Villegas et al., 2000). It seems that a similar mechanism may operate in the case of

Table 1. Peroxidatic activity of SDS-modified cytochrome $c$ incubated with peroxynitrite in $0.1 \mathrm{M}$ phosphate buffer.

The activity was determined as the rate of ABTS oxidation at $700 \mathrm{~nm}$. Activity of native cytochrome $c$ is included as reference; [cytochrome $c$ ] $=2.5 \mu \mathrm{M},[\mathrm{SDS}]=10 \mathrm{mM}$, [ABTS $=2 \mathrm{mM},\left[\mathrm{H}_{2} \mathrm{O}_{2}\right]=1 \mathrm{mM}$.

\begin{tabular}{lc}
\hline System & $\begin{array}{l}\text { Rate of ABTS } \\
\text { oxidation, } \mu \mathrm{M} / \mathrm{min}\end{array}$ \\
\hline Native cytochrome $c$ & 1.25 \\
Cytochrome $c+\mathrm{SDS}$ & 17.7 \\
$\begin{array}{l}\text { Cytochrome } c+\mathrm{SDS}+0.8 \mathrm{mM} \\
\text { peroxynitrite }\end{array}$ & 5.0 \\
$\begin{array}{l}\text { Cytochrome } c+\mathrm{SDS}+1.0 \mathrm{mM} \\
\text { peroxynitrite }\end{array}$ & 3.2 \\
$\begin{array}{l}\text { Cytochrome } c+\mathrm{SDS}+2.0 \mathrm{mM} \\
\text { peroxynitrite }\end{array}$ & 2.6 \\
\hline
\end{tabular}

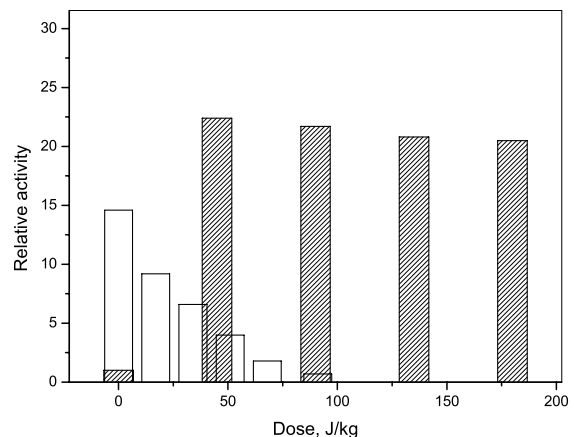

Figure 2. Relative peroxidatic activity of cytochrome $c$ irradiated at micromolar concentration in $\mathrm{N}_{2} \mathrm{O}$-saturated aqueous solution in the absence (dashed columns) or in the presence of $10 \mathrm{mM}$ SDS (empty columns), $\mathrm{pH}=7.0$ (5 $\mathrm{mM}$ phosphate buffer). Activity of native cytochrome $c$ is assumed as 1 .

other amino acid radicals formed in the vicinity of heme in SDS-modified cytochrome $c$ under oxidizing conditions. The primary radical sites near the heme center may also be transferred to other amino-acid residues important for the catalytic reaction. The overall effect observed is that the peroxidase-like activity of SDS-modified cytochrome $c$ decreases with an increase of the concentration of oxidizing species.

\section{Acknowledgement}

This work was partly supported by the State Committee for Scientific Research (KBN, Poland), grant 3 T09A 01525.

\section{REFERENCES}

Augusto O, Bonini MG, Amanso AM, Linares E, Santos CCX, de Menezes SL (2002) Free Rad Biol Med 32: 841859.

Bansal KM, Patterson LK, Fendler EJ, Fendler JH (1971) Int J Radiat Phys Chem 3: 321-331.

Barr DP, Gunther MR, Deterding LJ, Tomer KB, Mason RP (1996) J Biol Chem 271: 15498-15503.

Buxton GV, Greenstock CL, Helman WP, Ross AB (1988) Phys Chem Ref Data 17: 513-886.

Cassina AM, Hodara R, Souza JM, Thomson L, Castro L, Ischropoulos H, Freeman BA, Radi R (2000) J Biol Chem 275: 21409-21415.

Castro L, Eiserich JP, Sweeney S, Radi R, Freeman BA (2004) Arch Biochem Biophys 421: 99-107.

Chen Y-R, Deterding LJ, Sturgeon BE, Tomer KB, Mason RP (2002) J Biol Chem 277: 29781-29791.

Childs RE, Bardsley WG (1975) Biochem J 145: 93-103.

Diederix REM, Ubbink M, Canters GW (2002) Biochemistry 41: 13067-13077.

Diederix REM, Busson S, Ubbink M, Canters GW (2004) J Mol Catal B 27: 75-82.

Evers EL, Jayson GG, Swallow AJ (1978) J Chem Soc Faraday Trans I 74: 418-426.

Florence TMJ (1985) Inorg Biochem 23: 131-141. 
Floris R, Piersma R, Yang G, Jones P, Wever R (1993) Eur J Biochem 215: 767-775.

Gebicka L (2001) Res Chem Intermed 27: 717-723.

Gębicka L, Didik J (2003) Acta Biochim Polon 50, 815-823.

Gębicka L, Gebicki JL (1998) J Prot Chem 18: 165-171.

Gębicka L, Gębicki JL (2000) IUBMB Life 49: 11-15.

Goldstein S, Czapski G (1995) Inorg Chem 34: 4041-4048.

Goto Y, Hagihara Y, Hamada D, Hoshino M, Nishi I (1993) Biochemistry 32: 11878-11885.

Hamachi J, Fujita A, Kunitake T (1994) J Am Chem Soc 116: 8811-8812.

Herold S, Shivashankar K (2003) Biochemistry 42: 1403614046.

Hugdes MN, Nicklin HG (1968) J Chem Soc 450-452.

Kirsch M, Korth H-G, Wensing A, Sustman R, de Groot H (2003) Arch Biochem Biophys 418: 133-150.

Kluck RM, Bossy-Welzel E, Green DR, Newmeyer DD (1997) Science 275: 1132-1136.

Lawrence A, Jones CM, Wardman P, Burkitt MJ (2003) Biol Chem 278: 29410-29419.
Li P, Dijhawan D, Budihardjo I, Srinivasula SM, Ahmad M, Alnemri ES, Wang X (1997) Cell 91: 479-489.

Neta P, Huie RE, Ross AB (1988) J Phys Chem Ref Data 17: 1027-1284.

Oellerich S, Wackerbarth H, Hildebrandt P (2002) J Phys Chem B 106: 6566-6580.

Oellerich S, Wackerbarth H, Hildebrandt P (2003) Eur Biophys J 32: 599-613.

Otzen DE, Oliveberg M (2002) J Mol Biol 315: 1231-1240.

Pryor WA, Cueto R, Jin X, Koppenol WH, Ngu-Schwemlein M, Squadrito GL, Uppu PL, Uppu RM (1995) Free Rad Biol Med 18: 75-83.

Radi R, Thomson L, Rubbo H, Prodanov E (1991) Arch Biochem Biophys 288: 112-117.

Reynolds JA, Tanford C (1970) Proc Natl Acad Sci USA 66: 1002-1007.

Skulachev VP (1998) FEBS Lett 423: 275-280.

Villegas JA, Mauk AG, Vazquez-Duhalt R (2000) Chem Biol 7: $237-244$. 